\title{
Population structure of Aedes albopictus from La Réunion Island (Indian Ocean) with respect to susceptibility to a dengue virus
}

\author{
CHRISTOPHE PAUPY $\dagger$, ROMAIN GIROD $\$$ MAXIMIN SALVAN $\ddagger$, \\ FRANÇOIS RODHAIN $\dagger$ \& ANNA-BELLA FAILLOUX*† \\ †Unité d'Ecologie des systèmes vectoriels, Institut Pasteur, 25 rue du Dr Roux, 75724 Paris cedex 15, \\ France and $\ddagger$ Service de lutte antivectorielle, D.R.A.S.S. de La REUNION, 60 rue du Général de Gaulle, \\ 97400 Saint Denis, La Réunion
}

\begin{abstract}
Ten $\mathrm{F}_{1}$ Aedes albopictus samples collected from Réunion Island in the Indian Ocean were tested for oral susceptibility to dengue 2 virus and 20 were analysed for genetic polymorphism by starch gel electrophoresis. Data from infection rates defined two distinct geographical areas: east coast vs. west coast. Genetic differentiation was found to be dependent on ecological factors and the biological characteristics of Ae. albopictus. These results have implications for the vector ecology and pattern of migration, and have importance in the understanding of dengue transmission.
\end{abstract}

Keywords: Aedes albopictus, dengue, experimental infection, genetic differentiation, La Réunion Island, vector competence.

\section{Introduction}

Aedes albopictus (Skuse), the Asian 'tiger mosquito', is considered to be a vector of dengue viruses, the most important arthropod-borne viruses transmitted to humans by mosquitoes. This species seems to have originated in the forests of South-East Asia (Smith, 1956). Its ability to colonize diverse ecological settings may account for its wide distribution; it has spread as far west as Madagascar and the Seychelles and east through the Indomalayan and Oriental regions. However, changes in the urban environment due to human activity may drastically alter the population density of this species. Intensive urbanization created environmental conditions inappropriate for its proliferation. Ae. albopictus is commonly found in urban, rural and forested areas, and seems to cluster in and around parks, residential gardens and cemeteries. However, Ae. albopictus may be absent from densely crowded cities, which lack vegetation and outdoor breeding sites (Rudnick \& Hammon, 1960). Aedes aegypti, another vector of dengue viruses, has evolved in close association with man. In contrast, Ae. albopictus, a species without ecological specialization, may be involved in the transfer of enzootic forest viruses into inhabited areas. Estimation of differentiation with respect to vector capacity has provided insight into

*Correspondence. E-mail: afaillou@pasteur.fr epidemiological aspects of the disease and can be used to improve disease control (Tran Khanh et al., 1999; Vazeille-Falcoz et al., 1999; Paupy et al., 2000).

Dengue is caused by four serotypes, DEN-1, DEN-2, DEN-3, and DEN-4, which are usually maintained in an urban transmission cycle by Ae. aegypti. Since World War II, dengue epidemics have become more frequent and widespread and South-East Asia has experienced large urban dengue haemorrhagic fever (DHF) epidemics. In the last 30 years, the pattern of disease has changed, and the incidence of epidemic DHF has increased in most tropical countries. Ae. albopictus has been shown to be responsible for dengue fever in epidemics in South-East Asia (Russel et al., 1969), in southern China (Qiu et al., 1981), in Japan (Sabin, 1952) and in the Seychelles (Metselaar et al., 1980).

In the islands of the south-west Indian Ocean, dengue-like epidemics have been reported since 1872 (Cotholendy, 1873; Pougnet, 1890; MacCarthy \& Brent, 1946). Dengue outbreaks were observed in the Seychelles and Réunion between 1976 and 1979 (Metselaar et al., 1980; Coulanges et al., 1979) and in the Comoro Islands in 1984 and 1993 (Boisier et al., 1994). Epidemics due to Ae. aegypti have also been detected in East Africa: in Kenya (Johnson et al., 1982), Sudan (Hyams et al., 1986), Somalia (Saleh et al., 1985; Kanesa-Thasan et al., 1994), Djibouti (Rodier et al., 1996) and Mozambique (Gubler et al., 1986). The increase in air travel 
since World War II is one of the factors known to be involved in the worldwide resurgence of dengue fever (DF) and the emergence of DHF (Gubler, 1997). The dengue virus is readily disseminated from a dengueendemic area by competent mosquitoes and/or by dengue-infected travellers. The developing tourism industry in the islands of the south-west Indian Ocean is increasing travel between south-east Asia and Africa, thereby increasing the risk of introducing dengue viruses into dengue-free regions such as Réunion.

The island of Réunion, an overseas administrative region of France, lies in the Indian Ocean about $800 \mathrm{~km}$ east of Madagascar. It covers an area of approximately $2500 \mathrm{~km}^{2}$ and has about 700000 inhabitants. There are only two distinct seasons: a cool and dry winter from May to October and a hot and rainy summer from November to April. The windward east coast region, which is wetter than the west coast region, is notably less inhabited. Both Ae. aegypti and Ae. albopictus are present on Réunion. Before the implementation of DDT treatments for malaria control, from 1949 to 1953, Ae. aegypti was frequent in the urban coastal area (Hamon, 1953). In contrast, Ae. albopictus, which was probably introduced to Réunion by immigrants from Asia in the 17th and 18th centuries, has colonized natural and urban habitats previously occupied by Ae. aegypti (Mattingly, 1953). Insecticide treatment, aimed at preventing mosquitoes from breeding in urban areas, has had an effect on Ae. aegypti populations, which persist today as residual wild populations in the west coast region (Salvan \& Mouchet, 1994). The decline in Ae. aegypti populations was associated with Ae. albopictus infestation of unoccupied breeding sites. Ae. albopictus is now present at high densities colonizing both urban and rural biotopes. An epidemic of dengue fever started in the Seychelles in December 1976, in which dengue 2 virus and Ae. albopictus were implicated (Metselaar et al., 1980). In 1977, the epidemic reached Réunion and was attributed to Ae. albopictus (Kles et al., 1994); 30-35\% of the island's inhabitants, most of whom were living in the east coast region, showed DF symptoms (Mora, 1979). No dengue epidemic has since been recorded on Réunion. The dramatic increase in the incidence of dengue in tropical countries especially over the last several decades may be attributed to the increase in human travel and to uncontrolled population growth and urbanization. The problem of importation of mosquitoes and dengue viruses from viremic travellers (potential source of infection for local Ae. albopictus) into dengue-free zones is a major concern that should receive serious attention.

Ae. albopictus and Ae. aegypti are both present on Réunion. As both are effective vectors for dengue viruses, it is important to estimate the competence of mosquito populations and their dispersal rate (and indirectly, virus dissemination) by analysing the genetic differentiation of mosquito populations. Such studies are necessary for risk assessment before the implementation of any control programme.

\section{Materials and methods}

\section{Mosquito samples}

Twenty Ae. albopictus samples were collected from Réunion in October 1999 (Table 1, Fig. 1). Larvae or pupae were maintained until the adult stage in laboratory conditions (temperature $25 \pm 1{ }^{\circ} \mathrm{C}$, relative humidity $80 \pm 10 \%$ and photoperiod $12 \mathrm{~h})$. The adults $\left(\mathrm{F}_{0}\right.$ generation) obtained were allowed to blood feed on mice to enable them to produce eggs. Larvae were reared until the imago $\left(F_{1}\right.$ generation). The $F_{0}$ imagoes were stored at $-80^{\circ} \mathrm{C}$ until genetic analysis. We investigated the oral susceptibility to dengue 2 virus of $F_{1}$ females. The Paea strain of Ae aegypti was established from adults caught in the Paea district of Tahiti (French Polynesia), and has been maintained in our laboratory since 1994. This strain was used as a control for mosquito oral susceptibility to dengue viruses and as a mobility control for isoenzyme electrophoresis. The Ae. albopictus strain, Mada 15, established from a sample collected in March 1999 from Madagascar, was also used as a mobility control for isoenzyme electrophoresis.

\section{Experimental infection of mosquitoes}

For each $\mathrm{F}_{1}$ mosquito sample, two infection assays were performed at two-day intervals, when sufficient mosquitoes were available. The 5- to 7-day-old and non-bloodfed females were starved for $24 \mathrm{~h}$ before infection, in small plastic containers. They were allowed to feed for 20 min on an artificial meal maintained at $37^{\circ} \mathrm{C}$ in glass feeders covered with chicken skin (Vazeille-Falcoz et al., 1999). The infectious meal consisted of $2 / 3$ washed rabbit erythrocytes, $1 / 3$ virus suspension and a phagostimulant, ATP $\left(5 \times 10^{-3} \mathrm{M}\right)$. The viral suspension used for feeding had a final titre of $10^{8.2} \mathrm{MID}_{50} \quad(50 \%$ mosquito infectious dose for Ae. aegypti) per $\mathrm{mL}$ of a dengue-2 strain isolated in 1974 from a human serum sample from Bangkok (Thailand). Viral stocks were prepared as described by Vazeille-Falcoz et al. (1999). Fully engorged females were incubated for 14 days and allowed to feed on a $10 \%$ sugar solution. Dengue 2 virus was detected by an indirect immunofluorescence assay (IFA) using head squashes from surviving females. The Paea strain was used as an infectivity control (VazeilleFalcoz et al., 1999). The viral titre resulting in a mean of $90 \%$ infection of the Paea strain was determined before 
Table 1 Sites from which Aedes albopictus was sampled on Réunion in October 1999

\begin{tabular}{cllll}
\hline No. & Sample & \multicolumn{1}{c}{ Location } & Collection date & Breeding site \\
\hline East coast & & & & \\
1 & AND & Saint André & $10 / 08 / 99$ & Flower vase \\
2 & BEN & Saint Benoît & $10 / 07 / 99$ & Flower vase \\
3 & BRU1 & Grand Brûlé & $10 / 09 / 99$ & Tyre \\
4 & BRU2 & Grand Brûlé & $10 / 09 / 99$ & Tyre \\
5 & GLI & Ravine Glissant & $10 / 07 / 99$ & Tyre \\
6 & LAM & La Marine & $10 / 07 / 99$ & Abandoned boat \\
7 & MAR & Sainte Marie & $10 / 08 / 99$ & Empty oil drum \\
8 & PAN & Bras-Panon & $10 / 07 / 99$ & Flower vase \\
9 & PRO & La Providence & $10 / 11 / 99$ & Palm leaf \\
10 & ROS & Sainte Rose & $10 / 07 / 99$ & Flower vase \\
11 & SUZ & Sainte Suzanne & $10 / 08 / 99$ & Flower vase \\
West coast & & & & \\
12 & ERM & L'Ermitage & $10 / 11 / 99$ & Tyre \\
13 & LEU & Saint Leu & $10 / 11 / 99$ & Rock hole \\
14 & LOU & Saint Louis & $10 / 07 / 99$ & Tyre \\
15 & PAU & Saint Paul & $10 / 08 / 99$ & Tree hole \\
16 & PIE1 & Saint Pierre & $10 / 07 / 99$ & Tyre \\
17 & PIE2 & Saint Pierre & $10 / 07 / 99$ & Empty oil drum \\
18 & POR & Le Port & $10 / 08 / 99$ & Flower vase \\
19 & POS & La Possession & $10 / 06 / 99$ & Rock hole \\
20 & TAM & Le Tampon & $10 / 09 / 99$ & Flower vase \\
\hline
\end{tabular}

the infection of $F_{1}$ females. This titre was determined by infecting mosquitoes with serial dilutions of the viral stock. We determined the feeding suspension virus titre that resulted in the infection of $90 \%$ of the females and this titre was used to infect field-collected mosquitoes.

\section{Electrophoresis}

Each individual mosquito was ground in $25 \mu \mathrm{L}$ of distilled water. The sample was centrifuged (20 $000 \mathrm{~g}$ for 4 min at $4^{\circ} \mathrm{C}$ ) and the supernatant, which contained the soluble proteins, was subjected to starch gel electrophoresis in Tris-malate-EDTA (pH 7.4) buffer. Nine enzyme systems were studied: glutamate oxaloacetate transaminases (Got1 and Got2), glycerol-3-phosphate dehydrogenase (G-3-pdh), hexokinases (Hk1 and Hk2), malate dehydrogenase $(\mathrm{Mdh})$, malate dehydrogenase (NADP) (Mdhp-1), phosphoglucoisomerase (Pgi) and phosphoglucomutase (Pgm). Aedes aegypti Paea and Ae. albopictus Mada 15 were used as controls of electrophoretic mobility. For field-collected samples, alleles were numbered according to their mobility relative to that of the most common allele obtained at each locus for the control strains.

\section{Genetic analysis}

Genetic differentiation was analysed using GENEPOP software (version 3.1), as described by Raymond \&
Rousset (1995). $F_{\mathrm{IS}}$ and $F_{\mathrm{ST}}$ were calculated according to the formula of Weir \& Cockerham (1984). Heterozygote deficits were tested using a exact test procedure (Rousset \& Raymond, 1995). Genotypic associations between pairs of loci were tested for each sample. Genotypic differentiation was tested for each population by calculating the $P$-value of the $F_{\mathrm{ST}}$ estimate. The overall significance of multiple tests was estimated by Fisher's combined probability test (Fisher, 1970). The significance level of each test was adjusted for the number of tests run, using the sequential method of Bonferroni (Holm, 1979). Isolation by distance (Slatkin, 1993) was investigated in computing rank correlations between $F_{\mathrm{ST}}$ estimates calculated between pairs of samples and geographical distances. Partial Mantel one-sided tests in which $P$-values were determined by permutation procedures were used to estimate the significance of correlations (Smouse et al., 1986; Leduc et al., 1992).

\section{Results}

\section{Mosquito infection rates}

For the 10 mosquito $F_{1}$ samples tested, infection rates were between 18\% ((18)POR a) and 59\% ((12)ERM b), Table 2. The rates obtained were lower in each case than those obtained for the Paea control $(68.5 \%$ to $95.5 \%)$. For samples with two replicates ((12)ERM (13)LEU (16)PIE1 and (18)POR), infection rates were compared, 


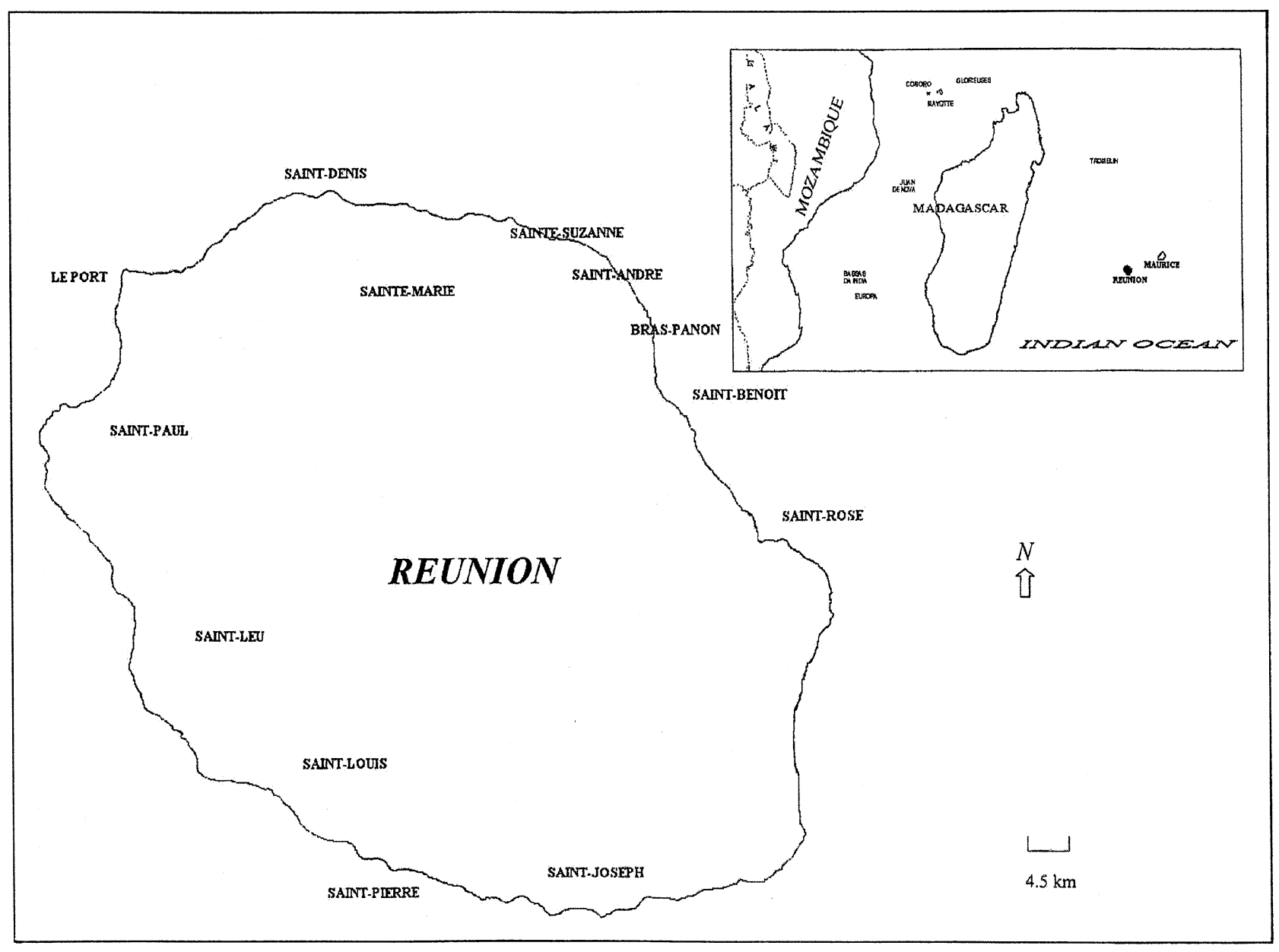

Fig. 1 Geographical locations on Réunion (Indian Ocean) from which Aedes albopictus was collected in October 1999.

using Fisher's exact test; $P$-values were not significant $(P>0.05)$, indicating that the replicates were homogeneous. We therefore pooled the two replicates of each sample for further analysis. The overall $P$-value obtained for analysis of all the samples was highly significant $\left(P<10^{-4}\right)$. We investigated the reasons for the observed differences in infection rate, by assigning samples to three different geographical groups: (1) the first group comprised four sites ((6)LAM (7)MAR (8)PAN and (11)SUZ) and corresponded to samples from the east coast; (2) the second group consisted of six samples ((12)ERM (13)LEU (15)PAU (16)PIE1 (18)POR and (19)POS) from the west coast; and (3) the third group representing a subgroup of the west coast corresponded to samples from the north-west coast ((12)ERM (13)LEU (15)PAU (18)POR and (19)POS). The null hypothesis of homogeneous infection rates was rejected $\left(P<10^{-4}\right)$ for the samples from the west coast and from the north-west coast, whereas the samples collected from the east coast showed no population differentiation $(P=0.46)$.

\section{Population structure}

Two of the nine loci investigated (G-3-pdh and $M d h p 1)$ were monomorphic or displayed limited polymorphism in most samples and were therefore not used in further analyses. Got1, Got2, Hkl, Hk2, Mdh, Pgi and Pgm showed codominant segregation in all samples.

Genotypic associations between pairs of loci within each sample were ruled out in the total analysis for all samples, taking multiple testing into account (Bonferroni sequential test $P>0.05$ ). We made 250 comparisons, and non-random associations between pairs of loci were rejected in all samples, taking multiple testing into account, except for the Hkl-Hk2 combination for the (12)ERM and (2)BEN samples. We investigated whether non-random allelic associations between pairs of polymorphic loci were due to selection or genetic drift by breaking down the total linkage disequilibrium $\left(D_{\mathrm{IT}}\right)$ into four indices, as described by Ohta (1982): $D_{\mathrm{IS}}$ and $D_{\mathrm{IS}}^{\prime}$ correspond to the disequilibrium created within populations, and $D_{\mathrm{ST}}$ and $D_{\mathrm{ST}}^{\prime}$ correspond to the 
Table 2 Infection rates with dengue 2 virus of 10 Aedes albopictus $\mathrm{F}_{1}$ samples from Réunion

\begin{tabular}{|c|c|c|c|c|c|}
\hline \multirow[b]{2}{*}{ No. } & \multirow[b]{2}{*}{ Sample } & \multirow[b]{2}{*}{ Replicate } & \multicolumn{2}{|c|}{ Percentage of infected females } & \multirow{2}{*}{$\begin{array}{l}\text { Probability of } \\
\text { homogeneity }\end{array}$} \\
\hline & & & Assay & Control $\dagger$ & \\
\hline \multicolumn{6}{|c|}{ East coast } \\
\hline 6 & LAM & $\mathrm{a}$ & $51.5(17 / 33)$ & $85.7(30 / 35)$ & 0.002 \\
\hline 7 & MAR & $\mathrm{a}$ & $37.2(19 / 51)$ & $79.6(39 / 49)$ & $<10^{-4}$ \\
\hline 8 & PAN & $\mathrm{a}$ & $50.0(15 / 30)$ & $95.5(43 / 45)$ & $<10^{-4}$ \\
\hline 11 & SUZ & a & $52.4(11 / 21)$ & $72.2(13 / 18)$ & 0.322 \\
\hline \multicolumn{6}{|c|}{ West coast } \\
\hline \multirow[t]{2}{*}{12} & ERM & a & $56.4(22 / 39)$ & $84.0(42 / 50)$ & 0.008 \\
\hline & & $\mathrm{b}$ & $59.1(39 / 66)$ & $91.6(76 / 83)$ & $<10^{-4}$ \\
\hline \multirow[t]{2}{*}{13} & LEU & $\mathrm{a}$ & $41.2(14 / 34)$ & $88.0(22 / 25)$ & 0.001 \\
\hline & & $\mathrm{b}$ & $30.1(19 / 63)$ & $79.6(39 / 49)$ & $<10^{-4}$ \\
\hline 15 & PAU & $\mathrm{a}$ & $31.9(26 / 84)$ & $68.6(59 / 86)$ & $<10^{-4}$ \\
\hline \multirow[t]{2}{*}{16} & PIE1 & $\mathrm{a}$ & $36.7(22 / 60)$ & $84.0(42 / 50)$ & $<10^{-4}$ \\
\hline & & $\mathrm{b}$ & $40.0(22 / 55)$ & $91.5(76 / 83)$ & $<10^{-4}$ \\
\hline \multirow[t]{2}{*}{18} & POR & $\mathrm{a}$ & $18.0(7 / 39)$ & $88.0(22 / 25)$ & $<10^{-4}$ \\
\hline & & $\mathrm{b}$ & $22.2(14 / 63)$ & $79.6(39 / 49)$ & $<10^{-4}$ \\
\hline 19 & POS & $\mathrm{a}$ & $38.7(24 / 62)$ & $68.6(59 / 86)$ & 0.001 \\
\hline
\end{tabular}

$\dagger$ Ae. aegypti Paea strain.

$\$$ Significant values are in italics. disequilibrium between populations. For all pairs of loci, $D_{\mathrm{IS}}$ was lower than $D_{\mathrm{ST}}$ and $D_{\mathrm{IS}}^{\prime}$ was larger than $D_{\text {ST }}^{\prime}$ (Table 3), indicating that the non-random genotypic associations found among Ae. albopictus populations were due to genetic drift rather than selection.

Hardy-Weinberg equilibrium was tested for each locus in each sample using the probability test. We tested each locus for each sample (120 probability tests); 29 tests were significant $(P<0.05), 20$ of which were related to the Hkl locus (Table 4). Hardy-Weinberg equilibrium (H0: random mating) was tested, the alternative hypothesis (H1) being heterozygote excess. The significant $P(<0.05)$ and $F_{\mathrm{IS}}$ values (close to +1$)$ obtained at the $H k l$ locus for all samples indicated heterozygote excess at this locus, which was probably subject to selection. Global tests considering all populations for each locus or considering all loci for each population were also performed: significant deviation from Hardy-Weinberg equilibrium $\left(P<10^{-4}\right)$ was observed in 18 of 20 samples. If $H k l$ was excluded from the analysis, only three samples ((7)MAR (18)POR and (3)BRU1) gave significant $P$-values. After
Table 3 Variance components of linkage equilibrium. Ohta's statistic values estimated for all combinations of loci

\begin{tabular}{|c|c|c|c|c|c|}
\hline \multirow[b]{2}{*}{ Comparison } & \multicolumn{2}{|c|}{ Within sample } & \multicolumn{2}{|c|}{ Between samples } & \multirow{2}{*}{$\begin{array}{c}\text { Total } \\
D_{\text {IT }}\end{array}$} \\
\hline & $D_{\text {IS }}$ & $D_{\mathrm{IS}}^{\prime}$ & $D_{\mathrm{ST}}$ & $D_{\mathrm{ST}}^{\prime}$ & \\
\hline$P G M-P G I$ & 0.00390 & 0.05706 & 0.01672 & 0.00017 & 0.05724 \\
\hline$P G M-G O T 1$ & 0.00161 & 0.05175 & 0.01444 & 0.00001 & 0.05175 \\
\hline$P G M-G O T 2$ & 0.00326 & 0.05906 & 0.01802 & 0.00033 & 0.05939 \\
\hline$P G M-M D H$ & 0.00722 & 0.05831 & 0.01369 & 0.00044 & 0.05876 \\
\hline$P G M-H K 1$ & 0.00071 & 0.02819 & 0.00925 & 0.00003 & 0.02822 \\
\hline$P G I-G O T 1$ & 0.00074 & 0.03626 & 0.01088 & 0.00001 & 0.03627 \\
\hline$P G I-G O T 2$ & 0.00156 & 0.05165 & 0.01641 & 0.00006 & 0.05171 \\
\hline$P G I-M D H$ & 0.00302 & 0.04800 & 0.01376 & 0.00030 & 0.04830 \\
\hline$P G I-H K 1$ & 0.00074 & 0.02025 & 0.00857 & 0.00009 & 0.02034 \\
\hline GOT1-GOT2 & 0.00047 & 0.04515 & 0.01229 & 0.00000 & 0.04516 \\
\hline$G O T 1-M D H$ & 0.00110 & 0.04300 & 0.01127 & 0.00006 & 0.04306 \\
\hline GOT1-HK1 & 0.00013 & 0.01373 & 0.00559 & 0.00000 & 0.01373 \\
\hline$G O T 2-M D H$ & 0.00269 & 0.05582 & 0.01540 & 0.00036 & 0.05618 \\
\hline GOT2-HK1 & 0.00046 & 0.02639 & 0.00922 & 0.00003 & 0.02642 \\
\hline$M D H-H K 1$ & 0.00100 & 0.02280 & 0.00770 & 0.00010 & 0.02290 \\
\hline
\end{tabular}

(C) The Genetics Society of Great Britain, Heredity, 87, 273-283. 


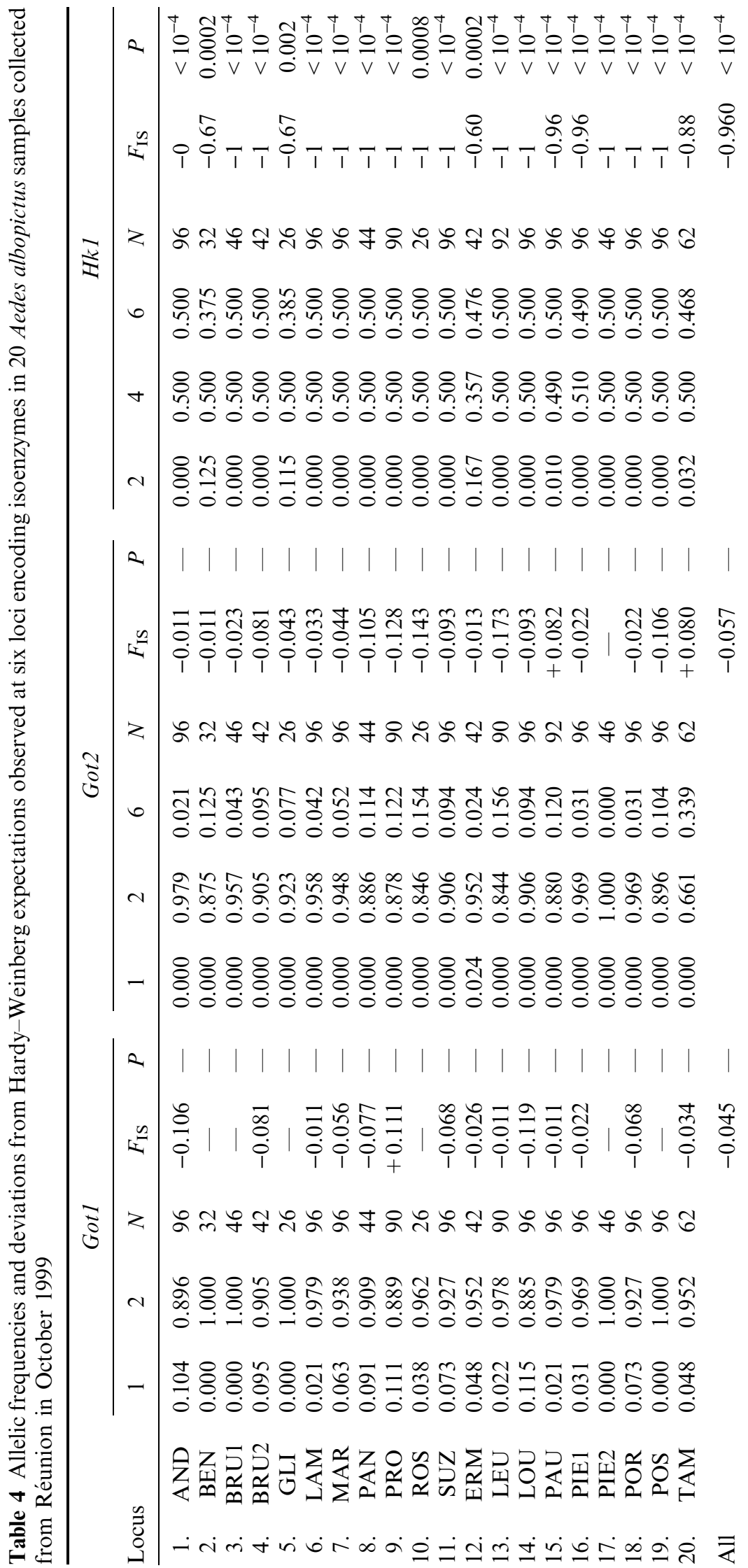

(C) The Genetics Society of Great Britain, Heredity, 87, 273-283. 


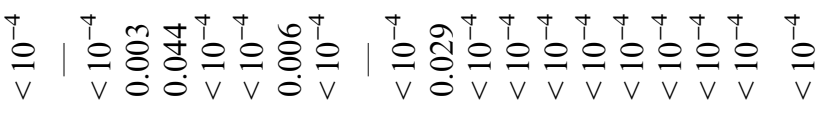

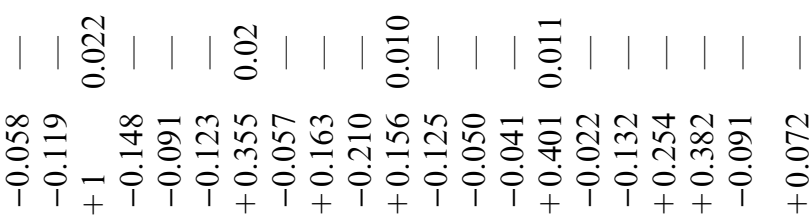

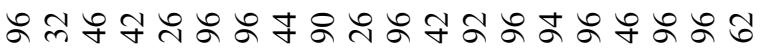

舟等等

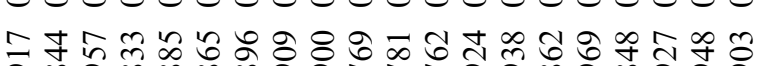

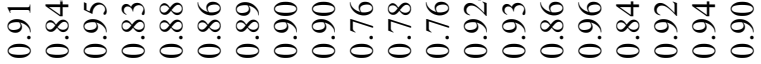

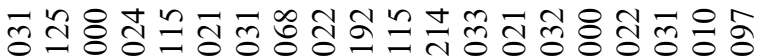
0000000000000000000 | |

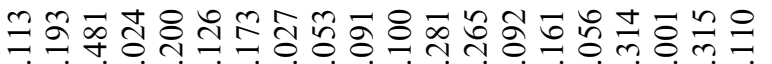
o o it o o i i o i o o o o o o o i i i

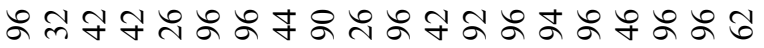

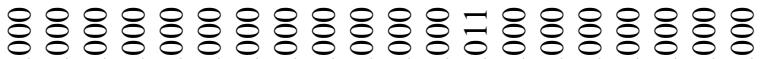
000000000000000000000

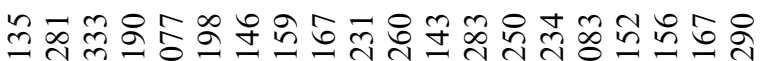
00000000000000000000

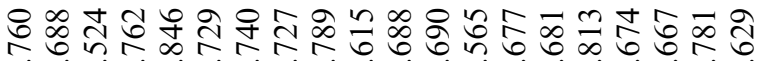
00000000000000000000

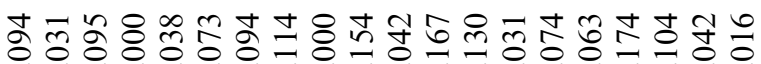
000000000000700000000

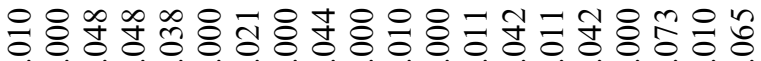
00000000000000000000

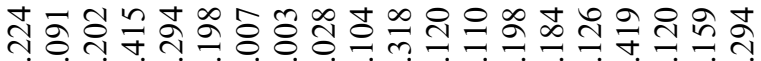

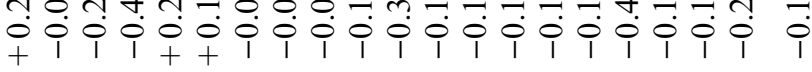

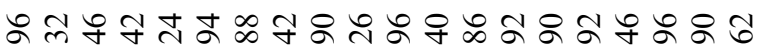

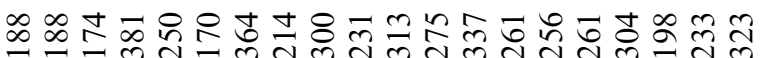
00000000000000000000

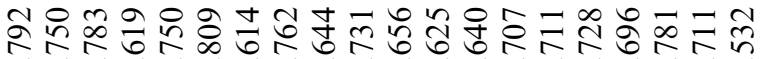
00000000000000000000

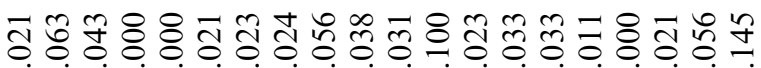
00000000000000000000

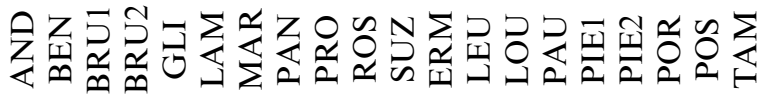
-

(C) The Genetics Society of Great Britain, Heredity, 87, 273-283. 
application of the Bonferroni procedure, these results were not significant. For this reason, Hkl was excluded from the analysis.

Significant differentiation, evaluated by estimating $F_{\mathrm{ST}}$, was observed in analysis of the 20 samples $\left(F_{\mathrm{ST}}=+0.019, P<0.001\right)$. We investigated the pattern of differentiation by considering various groups of samples defined on the basis of geographical and environmental factors (Table 5). The west coast of Réunion is drier and more heavily populated than the very humid east coast. The two samples from SaintDenis, the largest town on the island ((9) PRO and (7)MAR) were not significantly differentiated $\left(F_{\mathrm{ST}}=+0.001, P>0.05\right)$. If samples from the west and east coasts of Réunion (excluding (9)PRO and (7)MAR) were analysed separately, high $F_{\mathrm{ST}}$ values $(+0.025$ for the west coast and +0.013 for the east coast) with significant $P$-values $(P<0.05)$ were obtained. However, the estimated $F_{\mathrm{ST}}$ value for the west coast was twice that for the east coast. The relationship between gene flow and geographical distances can be examined by the rank correlation between $F_{\mathrm{ST}} /\left(1-F_{\mathrm{ST}}\right)$ estimates and log distance computed for all pairs of samples. This correlation was negative when considering samples from the west coast $(b=-0.005)$ and positive when analysing samples from the east coast $(b=+0.0005)$. However, in both cases, the correlation was not significant $(P>0.05)$ indicating that intensity of gene flow was independent of distance between samples. Samples collected from the north-west coast $\left(F_{\mathrm{ST}}=+0.015, P<0.001\right)$ and the north-east coast $\left(F_{\mathrm{ST}}=+0.01, P<0.05\right)$ were less differentiated than those from the south-west coast $\left(F_{\mathrm{ST}}=+0.049\right.$,
$P<0.001)$ and the south-east coast $\left(F_{\mathrm{ST}}=+0.023\right.$, $P<0.001)$.

We analysed samples from the north-west coast as a function of the ecological characteristics of the breeding sites sampled (rural vs. urban). Genetic differentiation was high $\left(F_{\mathrm{ST}}=+0.025\right)$ and significant $(P<0.05)$ for samples collected in urban areas, whereas samples from rural areas were not differentiated $\left(F_{\mathrm{ST}}=+0.0009\right.$, $P>0.05)$.

\section{Discussion}

In this study, we investigated the population structure of Ae. albopictus on Réunion using phenotypic (susceptibility to dengue 2 virus) and genotypic (isoenzyme polymorphism) markers. We found that extrinsic factors (climatic, geographical and human density) and intrinsic factors related to mosquito bionomics (host preference) affected the genetic structure and vector competence of Ae. albopictus populations.

The oral susceptibility of Ae. albopictus to dengue virus depends on the serotype and geographical origin of the virus (Rosen et al., 1985). The vector competence of Ae. albopictus populations for dengue viruses varies widely (Boromisa et al., 1987). In our study, the 10 populations experimentally infected with dengue 2 virus differed in infection rates. These data suggest that there is a higher level of variability in the oral susceptibility to dengue 2 virus of mosquito populations on Réunion and therefore, that there is intensive local differentiation of mosquitoes. Populations from the east coast seem to be more susceptible to dengue than those from the west coast. In addition, heterogeneity was observed in the

Table 5 Population differentiation of Aedes albopictus on Réunion

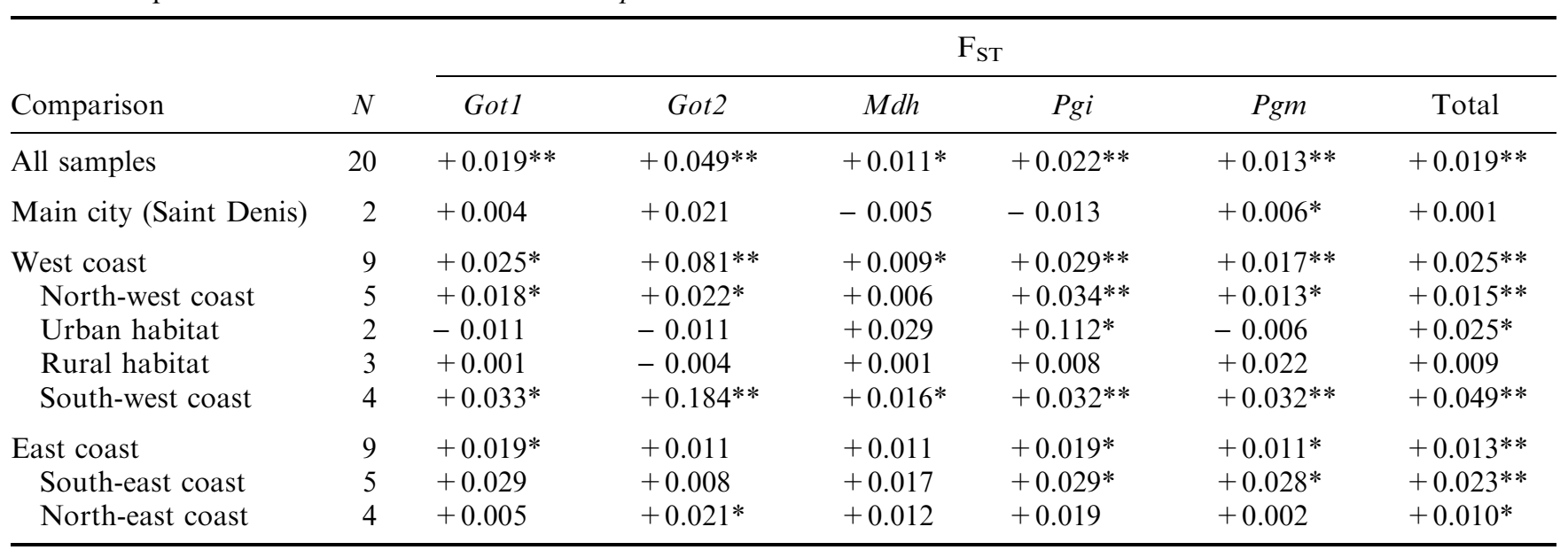

$F_{\mathrm{ST}}$, fixation index.

$N$, sample size.

$* P<0.05 ; * * P<0.001$. 
infection rates of samples from the west coast whereas those from the east coast displayed similar infection rates. During the dengue 2 outbreak in 1977-78, the more heavily populated west coast presented fewer DF cases than the east coast (Mora, 1979). Most international trade passed via the main harbour, Le Port, and the international airport at Saint-Denis. The most likely sites for the introduction of dengue viruses from dengue endemic/epidemic zones, as occurred in 1977, are therefore the harbour and the airport, where mosquitoes have been found to be less susceptible to dengue infection.

Réunion is a very hilly volcanic island. This results in climatic differences between the west and east coasts. The east coast, which is not protected by the coral barrier reef, has a narrow coastal area, limiting urban development. This coast is subjected to the trade winds, which bring large amounts of rainfall, creating numerous natural breeding sites suitable for Ae. albopictus. Larvae colonize cut bamboo, leaf axils, rock pools and tree holes. Genetic exchanges frequently occur between close populations and the level of population differentiation tends to be low throughout the year. This pattern of extensive dispersal of the mosquito (i.e. low differentiation) is consistent with a high level of dispersal of dengue-infected Ae. albopictus and thus, with a large number of human dengue cases. In the east coast region, the number of available breeding sites does not seem to be restricted but human density may affect the level of dispersal of mosquitoes, which must find hosts for blood feeding. However, if human hosts are not available, as in the uninhabited south-east region (with the volcano, Le Piton de la Fournaise), Ae. albopictus feeds instead on pigs, dogs and chickens (Sullivan et al., 1971). This leads to a higher level of differentiation (twice that in the north-east region) expressed as the preference of Ae. albopictus mosquitoes for mammalian hosts other than humans. This species seems to be an opportunistic blood feeder capable of feeding on a wide variety of hosts.

The lack of precipitation on the west coast during the dry season causes the drying up of natural breeding sites. Recurrent extinction events tend to reduce intranatural site genetic variability and increase inter-natural site variability. The presence of the coral reef in the west coast has led to intensive urbanization of this area and the development of tourism infrastructures. In urban areas, Ae. albopictus is able to colonize the human-built habitat, altering its natural ecology. This species is present in parks, residential gardens and cemeteries. Factors other than the ecological characteristics of the area seem to influence the distribution of Ae. albopictus, indicating that humans may be involved in the spread of this species. On the west coast, the availability of human hosts in which the mosquito can complete its gono- trophic cycle reduces species dispersal. In addition, due to good sanitation conditions, which limit the number of artificial breeding sites, the main cities are unsuitable for the proliferation of Ae. albopictus populations. Mosquitoes tend to identify only oviposition sites similar to those on which they were born, and to lay their eggs in the same or neighbouring breeding sites. So, differentiation among populations is intense, even if populations are separated by only a few kilometres. Black et al. (1988a) also showed that Ae. albopictus samples collected from neighbouring areas within a city were 3-4 times more differentiated than populations from other areas, suggesting extensive local differentiation. Genetic drift was found to be associated with the establishment of a small number of founding individuals, in some cases subjected to insecticidal control, which is probably more common in populated areas.

The most typical larval habitats of Ae. albopictus appear to be man-made containers and tree-holes. In the urban environment, discarded plastic containers and tyres collect rainwater, making ideal larval habitats. On the north-west coast, the mosquito populations sampled from artificial breeding sites were more highly differentiated than those collected from natural breeding sites. In rural areas, Ae. albopictus breeds in a large variety of containers so the distribution of oviposition sites is considerably more continuous than that in cleaned urban areas (Black et al., 1988b). This results in a higher level of differentiation in populations from urban areas.

Ae. albopictus often shows a discontinuous distribution, with localized breeding units, probably due largely to the low dispersal rate of this species (a mean distance of $104 \mathrm{~m}$ ) (Bonnet \& Worchester, 1946; Mori, 1979). Local selection and low levels of migration facilitate the emergence of genetically different populations. However, extrinsic factors, such as changes in climatic and geographical characteristics, and human density appear to modulate these patterns. To identify more clearly the factors that affect the genetic structure of Ae. albopictus populations, studies should be carried out on populations from isolated areas, such as islands in the Indian Ocean. The influence of humans on Ae. albopictus genetic structure should be studied in a geographical situation in which the physical barriers to gene flow are readily distinguishable and thus the role of human displacements in mosquito genetic exchanges could be determined.

\section{Acknowledgements}

This research was supported by the programme "l'Air, l'Environnement et la Santé" of the Pasteur Institute. We would like to thank Marie Vazeille, Laurence 
Mousson and Nadia Ayad for technical assistance. We would also like to thank the staff of the D.R.A.S.S. (Direction Régionale des Affaires Sanitaires et Sociales) on Réunion for their invaluable help in mosquito collections.

\section{References}

BLACK, W. C., IV, FERRARI, J. A., RAI, K. S. AND SPRENGER, D. 1988a. Breeding structure of a colonizing species: Aedes albopictus (Skuse) in the United States. Heredity, 60, $173-181$

BLACK, W. C., IV, HAWLEY, W. A., RAI, K. S. AND CRAIG, G. B., JR. 1988b. Breeding structure of a colonizing species: Aedes albopictus (Skuse) in peninsular Malaysia and Borneo. Heredity, 61, 439-446.

BOISIER, P., MORVAN, J. M., LAVENTURE, S., CHARRIER, N. ET AL. 1994. Epidémie de dengue 1 sur l'île de La Grande Comore (République Fédérale Islamique des Comores), mars-mai 1993. Ann. Soc. Belge Méd. Trop., 74, 217-229.

BONNET, D. D. AND WORCHESTER, D. J. 1946. The dispersal of Aedes albopictus in the territory of Hawaii. Am. J. Trop. Med. Hyg., 26, 465-476.

BOROMISA, R. D., RAI, K. S. AND GRIMSTAD, P. R. 1987. Variation in the vector competence of geographic strains of Aedes albopictus for dengue-1 virus. J. Am. Mosquito Control Assoc., 3, 378-386.

COTHOLENDy. 1873. Relation de l'épidémie de dengue qui a régné à Saint Denis (Réunion) pendant les mois de février, mars, avril et mai 1873. Arch. Méd. Navale, 20, 190.

COUlANGes, P., ClerC, Y., JOUSSET, F. X., RODHAIN, F. ET AL. 1979. Dengue à la Réunion. Isolement d'une souche à l'Institut Pasteur de Madagascar. Bull. Soc. Path. Exo., 72, 205-209.

FISHER, R. A. 1970. Statistical Methods for Research Workers, 4th edn. Olivier and Boyd, Edinburgh.

GUBLER, D. J. 1997. Dengue and dengue haemorrhagic fever: its history and resurgence as a global public health problem. In: Gubler, D. J. and Kuno, G. (eds) Dengue and Dengue Haemorrhagic Fever, pp. 1-22. CAB International, Wallingford, UK.

GUbler, D. J., SATHER, G. E., KUNO, G. AND CABRAL, J. R. 1986. Dengue-3 transmission in Africa. Am. J. Trop. Med. Hyg., 35, $1280-1284$

HAMON, J. 1953. Etudes biologique et systématique des Culicinae de l'Ile de La Réunion. Mémoires de l'Institut Scientifique de Madagascar, Série E, 4, 521-541.

HOLM, S. 1979. A simple sequentially rejective multiple test procedure. Scand. J. Stat., 6, 65-70.

HYAMS, K. C., OLDFIELD, E. C., SCOTT, R. M., BOURGEOIS, A. L. ET AL. 1986. Evaluation of febrile patients in Port-Sudan, Sudan: isolation of dengue virus. Am. J. Trop. Med. Hyg., 35, $860-865$.

JOHNSON, B. K., MUSOKE, S., CHENG, D., GICHOGO, A. ET AL. 1982. Dengue-2 virus in Kenya. Lancet, 2, 208-209.

KANESA-THASAN, N., IACONO-CONNORS, L., MAGILL, A., SMOAK, B. ET AL. 1994. Dengue serotype 2 and 3 in US forces in Somalia. Lancet, 343, 678.
KLes, V., Michault, A., Rodhain, F., MEVel, F. ET AL. 1994. Enquêtes sérologiques concernant les arboviroses à Flaviviridae sur l'île de la Réunion (1971-89). Bull. Soc. Path. Exo., 87, 71-76.

LEDUC, A., DRAPEAU, P., BERGERON, Y. AND LEGENDRE, P. 1992. Study of partial components of forest cover using partial Mantel tests and path analysis. J. Veget. Sci., 3, 69-78.

MACCARTHY, D. D. AND BRENT, R. H. 1946. An account of an outbreak of dengue fever in Dzaoudzi, Comoro Islands, January 1943. East African Med. J., 20, 293-298.

MAtTingly, P. F. 1953. The subgenus Stegomyia (Diptera: Culicidae) in the Ethiopian region. II. Distribution of species confined to the East South African sub-region. Bull. Br. Mus. (Nat. Hist.), 3, 1-65.

METSElAAR, D., GRAINGER, C. R., OEI, K. G., REYNOLDS, D. G. ET $A L$. 1980. An outbreak of type 2 dengue in the Seychelles, probably transmitted by Aedes albopictus (Skuse). Bull. W.H.O., 58, 937-943.

MORA, B. 1979. L'épidémie de dengue à l'Ile de la Réunion en 1977-78. MSc Thesis, Université de Bordeaux II.

MORI, M. 1979. Effects of larval density and nutrition on some attributes of immature and adult Aedes albopictus. Trop. Med., 21, 85-103.

OHTA, т. 1982. Linkage disequilibrium due to random genetic drift in finite subdivided populations. Proc. Natl. Acad. Sci. U.S.A., 79, 1940-44.

PAUPY, C., VAZEILlE-FAlCOZ, M., MOUSSON, L., RODHAIN, F. ET AL. 2000. Aedes aegypti in Tahiti and Moorea (French Polynesia): isoenzyme differentiation in the mosquito population according to human population density. Am. J. Trop. Med. Hyg., 62, 217-224.

POUGNeT, v. 1890. Note de l'épidémie de dengue qui a régné à Port-Louis en 1872-1873. Bull. Soc. Méd. Ile Maurice, 8, 448-450.

QIU, F., ZHANG, H., SHAO, L., LI, X. ET $A L$. 1981. Studies on the rapid detection of dengue virus antigen by immunofluorescence and radioimmunoassay. Chin. Med. J., 94, 653-658.

RAYMOND, M. AND ROUSSET, F. 1995. GENEPOP (version 1.2): population genetics software for exact tests and ecumenicism. J. Hered., 86, 248-249.

RODIER, G. R., GUBlER, D. J., COPE, S. E., CROPP, C. B. ET AL. 1996. Epidemic dengue-2 in the city of Djibouti 1991-92. Trans. Royal Soc. Trop. Med. Hyg., 90, 237-240.

RoSen, L., ROZEBOOM, L. E., GUbler, D. J., LIEN, J. C. ET $A L$. 1985. Comparative susceptibility of mosquito species and strains to oral and parenteral infection with dengue and Japanese encephalitis viruses. Am. J. Trop. Med. Hyg., 34, 603-615.

ROUSSET, F. AND RAYMOND, M. 1995. Testing heterozygote excess and deficiency. Genetics, 140, 1413-1419.

RUDNICK, A., AND HAMMON, w. MC. D. 1960. Newly recognized Aedes aegypti problems in Manila and Bangkok. Mosquito News, 20, 247-249.

RUSSEl, P. K., QUY, D. V., NISALAK, A., SIMASATHIEN, P. ET $A L$. 1969. Mosquito vectors of dengue viruses in South Vietnam. Am. J. Trop. Med. Hyg., 18, 455-459.

SABIN, A. B. 1952. Research on dengue during World War II. Am. J. Trop. Med. Hyg., 1, 30-50. 
SALEH, A. H., HASSAN, A., SCOTT, R. MC. N., MELLICK, P. W. ET $A L$ 1985. Dengue in north-east Africa. Lancet, 2, 211-212.

SAlvan, M. AND mouchet, J. 1994. Aedes albopictus et Aedes aegypti à l'Ile de la Réunion. Ann. Soc. Belge Méd. Trop., 74, 323-326.

SLATKIN, M. 1993. Isolation by distance in equilibrium and non-equilibrium populations. Evolution, 47, 264-279.

SMITH, C. E. G. 1956. The history of dengue in tropical Asia and its probable relationship to the mosquito Aedes aegypti. J. Trop. Med. Hyg., 59, 243-251.

SMOUSE, P. E., LONG, J. L. AND SOKAL, R. R. 1986. Multiple regression and correlation extensions of the Mantel test of matrix correspondence. Syst. Zool., 35, 627-632.

SUllivan, M. F., GOULD, D. J. AND MANEECHAI, S. 1971. Observations on the host range and feeding preferences of Aedes albopictus (Skuse). J. Med. Entomol., 8, 713-716.

TRAN KHANH, T., VAZEILlE-FALCOZ, M., MOUSSON, L., TRAN HUU, H. ET AL. 1999. Aedes aegypti in Ho Chi Minh City (Viet Nam): susceptibility to dengue 2 virus and genetic differentiation. Trans. Royal Soc. Trop. Med. Hyg., 93, 581-586.

VAZEILlE-FALCOZ, M., MOUSSON, L., RODHAIN, F., CHUNGUE, E. $E T A L .1999$. Variation in oral susceptibility to dengue type 2 virus of populations of Aedes aegypti from the Islands of Tahiti and Moorea, French Polynesia. Am. J. Trop. Med. Hyg., 60, 292-299.

WEIR, B. S. AND COCKERHAM, C. C. 1984 . Estimating $F$-statistics for the analysis of population structure. Evolution, 38, 1358-1370. 